\title{
Uma análise do trabalho intermitente à luz do direito à inclusão socioeconômica
}

\author{
Rodrigo Goldschmidt ${ }^{1}$ \\ Beatriz de Felippe Reis ${ }^{2}$
}

\begin{abstract}
RESUMO
O presente artigo discute o contrato de trabalho intermitente, instituído pela Lei $\mathrm{n}^{\circ} 13.467 / 2017$, também conhecida como "lei da reforma trabalhista", sob a ótica do direito à inclusão socioeconômica. Busca-se, baseado em um método dedutivo, pautado na análise crítica da doutrina e da legislação sobre a matéria, associado a uma análise do cenário econômico brasileiro, verificar se o trabalho intermitente efetivamente promove uma inclusão socioeconômica do trabalhador. Ao final, tendo como pano de fundo o trabalho digno, o presente estudo propõe algumas alternativas para a geração de trabalho e renda para o trabalhador brasileiro.
\end{abstract}

Palavras-chave: inclusão socioeconômica. Trabalho digno. Trabalho intermitente.

\section{ABSTRACT}

This article discusses the intermittent labor contract, instituted by Law n ${ }^{\circ}$ 13.467/2017, also known as "law of labor reform", from the perspective of the right to socioeconomic inclusion. Based on the deductive method, based on a critical analysis of the doctrine and legislation on the matter, associated to an analysis of the Brazilian economic scenario, this article checks if the intermittent work effectively promotes a socioeconomic inclusion of worker. In the end, in the context of decent work, the present study proposes some alternatives for the generation of employment and income for the Brazilian worker.

Keywords: socioeconomic inclusion. Decent work. Intermittent work.

\section{INTRODUÇÃO}

No Brasil, a fim de enfrentar a crise econômica e a elevada taxa de desemprego, que já atinge mais de 13 milhões de pessoas, ${ }^{3}$ foi aprovada em 2017 a Lei no 13.467/2017. Segundo o governo brasileiro, somente com a modernização da legislação trabalhista, que estava em dissonância com o mercado, seria possível promover a geração de emprego.

Nesse contexto, a referida lei alterou diversos dispositivos da Consolidação das Leis do Trabalho (CLT) e passou a prever o trabalho intermitente e a possibilidade de terceirização na atividade-fim. Partindo disso, o presente artigo abordará o trabalho intermitente, previsto de forma expressa, no artigo 443, $\S 3^{\circ}$ e artigo 452-A, ambos da CLT.

\footnotetext{
${ }^{1}$ Pós-Doutor em Direito pela PUC/RS. Doutor em Direito pela UFSC. Professor e Pesquisador do PPGD Mestrado em Direito - UNESC. Coordenador do GP - DIREITO DO TRABALHO UNESC. Juiz do Trabalho Titular de Vara do TRT12. UNESC. rodrigo.goldschmidt@trt12.jus.br.

${ }^{2}$ Mestranda em Direito no PPGD/UNESC. Especialista em Direito do Trabalho pela UNISINOS. Graduada em Ciências Jurídicas e Sociais pela UFRGS. Pesquisadora junto ao GP - DIREITO DO TRABALHO UNESC. Analista Judiciário do TRT4. UNESC. bialippe @ hotmail.com.

${ }^{3}$ Informação contida no parecer ao Projeto de Lei no ${ }^{\circ}$ 6.787/2016.
} 
Para tanto, num primeiro momento será feita uma breve abordagem sobre o contexto em que antecedeu a aprovação da reforma trabalhista. A seguir, serão apresentadas algumas considerações acerca do trabalho intermitente. Na sequência, proceder-se-á a uma análise desta modalidade de contratação à luz do direito à inclusão socioeconômica. E, ao final, será apresentada uma alternativa que permita a inclusão do trabalhador, por meio da geração de trabalho e renda, sem que este tenha sua dignidade vilipendiada.

Quanto à metodologia, de acordo com Marconi e Lakatos (2003, p. 106-183), o método de abordagem será o dedutivo, partindo de uma análise do geral para o particular. Como método de procedimento, adotar-se-á o monográfico e, quanto à técnica de pesquisa, será utilizada a pesquisa bibliográfica.

Por fim, a presente pesquisa terá por objetivo fazer avançar a discussão sobre a eficácia do trabalho intermitente, enquanto nova modalidade contratual introduzida no sistema jurídico trabalhista, com vistas a promover a redução do desemprego ou da informalidade.

\section{ANTECEDENTES DA APROVAÇÃO DA REFORMA TRABALHISTA E DO CONTRATO DE TRABALHO INTERMITENTE}

A fim de superar a crise financeira de 2008, que teve entre as suas causas o avanço do neoliberalismo, muitos países, dentre eles o Brasil, vêm impondo a flexibilização das leis trabalhistas ao lado de medidas de austeridade fiscal ${ }^{4}$, enquanto ações necessárias para a retomada do crescimento econômico e para o enfrentamento do desemprego.

Nesse contexto, as ideias de modernização e flexibilização se fortaleceram e passaram a ser defendidas como algo necessário ou até mesmo inevitável para o aumento da produtividade ou de competitividade no cenário global. O Direito do Trabalho, por sua vez, adquiriu status de vilão, encarado como entrave à lógica do mercado mundial, sendo alvo de ataques desde então (MAEDA, 2017, p. 317).

Dentro dessa tendência flexibilizante, o Congresso Nacional recentemente aprovou a Lei $\mathrm{n}^{\mathrm{o}}$ 13.467/2017, de 13 de julho de 2017, também conhecida como "lei da

\footnotetext{
${ }^{4}$ No Brasil, a principal medida de austeridade fiscal foi aprovada em 2016 pelo Congresso Nacional, o qual promulgou a Emenda Constitucional 95, que limita por 20 anos os gastos públicos. A PEC 55/2016, encaminhada pelo governo de Michel Temer ao Legislativo, teve por objetivo equilibrar as contas públicas por meio de um rígido mecanismo de controle de gastos. O regime valerá para os orçamentos fiscal e da seguridade social e para todos os órgãos e Poderes da República.
} 
reforma trabalhista", que alterou a CLT, a fim de adequar a legislação às novas relações de trabalho. ${ }^{5}$

Assim, a reforma foi apresentada como um pré-requisito indispensável para a geração de empregos e para tornar o país mais competitivo. Durante a tramitação do projeto de lei que resultou na reforma, o Deputado Rogério Marinho relatou a questão nos seguintes termos:

Reforçamos que o objetivo que pretendemos alcançar com essa reforma é o de modernizar as relações do trabalho, sem que haja precarização do emprego. Não mais podemos aceitar que as rígidas regras da CLT impeçam a absorção pelo mercado de trabalho dos milhões de brasileiros que integram as estatísticas oficiais do desemprego, do subemprego e dos que desistiram de procurar por um emprego, após anos de busca infrutífera por uma ocupação no mercado (CÂMARA DOS DEPUTADOS, 2017, p. 49).

Com relação ao tema, interessante destacar os estudos realizados pelos economistas Branco e Miebach, a partir do relatório elaborado pela Organização Internacional do Trabalho (OIT), em 2015, acerca das perspectivas sociais e de emprego no mundo, com enfoque sobre a mudança nas modalidades do emprego. Nesse sentido:

[...] estudos realizados pela OIT utilizando dados de mais de 100 países indicam que não há significância estatística na relação entre a rigidez da legislação trabalhista e o nível de emprego. O fato é que os processos econômicos são complexos, e o crescimento econômico deriva das interações entre diversas variáveis, tais como o tipo de inserção internacional de cada país, as condições dos mercados internacionais, as transformações tecnológicas, a natureza e o funcionamento das instituições, os distintos papéis desempenhados pelos salários, entre outras. Dessa forma, o crescimento econômico se configura muito mais como um indutor do emprego (dado um determinado sistema de relações laborais) do que como o resultado das condições institucionais que regulam as relações de trabalho (BRANCO; MIEBACH, 2018, p. 19-20).

Assim, percebe-se que a relação entre a reforma e a geração de empregos não ocorre de forma automática. Basta lembrar que o Brasil vivenciou o ápice do seu desenvolvimento e apogeu da economia entre os anos de 2010 e 2014, sob a vigência da mesma legislação trabalhista que passou a ser apontada como responsável pelo elevado nível de desemprego.

\footnotetext{
${ }^{5}$ Há quem sustente que a chamada "reforma trabalhista" em verdade não ocorreu. Nesse sentido, a Juíza do Trabalho Valdete Souto Severo, em entrevista concedida à Fundação de Economia e Estatística do RS, declarou que "a reforma da CLT não foi feita. Não há como falar em 'reforma', quando mais de 200 dispositivos são alterados, e todos eles, sem exceção, têm o objetivo (declarado pelos "pais" da Lei 13.467/2017) de proteger empregadores, ou seja, subvertem a razão histórica pela qual temos uma legislação trabalhista." (SEVERO, 2018, p. 13). Compartilhando dessa concepção, a professora da Universidade Federal do Paraná, Aldacy Rachid Coutinho, qualificou a Lei $\mathrm{n}^{\circ} 13.4672017$ como aquilo que ela chama de 'contrarreforma trabalhista' (ORDEM DOS ADVOGADOS DO BRASIL, 2017).
} 
Feitos estes breves apontamentos sobre o cenário político e econômico que antecedeu a aprovação da Lei $n^{\circ}$ 13.467/2017, abordar-se-á uma das principais "inovações" trazidas pela reforma como medida de redução do desemprego ou da informalidade: o contrato de trabalho intermitente.

\section{CONCEITUAÇÃO DO TRABALHO INTERMITENTE}

O contrato de trabalho intermitente foi recentemente introduzido no Brasil, ${ }^{6}$ tal como "vem sendo introduzido nas legislações de países em crise econômica, como Itália, Espanha e Portugal, com o objetivo de tornar as suas empresas mais competitivas no mercado exterior e criar mais empregos.” (PINHEIRO, 2017, p. 189).

Seguindo esta lógica, o parecer da Câmara, ao tratar do trabalho intermitente, estimou que com esta medida poderá ser gerado, nos próximos 10 anos, cerca de 14 milhões de postos de trabalho formais, além de impactar no fomento ao primeiro emprego, na redução da evasão escolar e na ampliação da renda familiar (CÂMARA DOS DEPUTADOS, 2017, p. $50)$.

Nesse contexto, surgiu a concepção de trabalho intermitente, previsto na nova redação dos artigos $443, \S 3^{\circ}$ e $452-\mathrm{A}$, ambos da CLT, ${ }^{7}$ como uma modalidade de contrato de trabalho.

Da leitura dos mencionados dispositivos, verifica-se que o principal não está expresso, embora esteja implícito: o trabalhador receberá apenas pelas horas efetivamente trabalhadas, o que gera uma grande insegurança (MAEDA, 2017, p. 318).

Ou seja, "o trabalho intermitente é tipo de emprego sem compromisso de prover renda, o que rompe com o paradigma de obrigações contratuais no âmbito do Direito do Trabalho.” (PINHEIRO, 2017, p. 198). Isso porque, “a garantia de que o valor horário do

\footnotetext{
${ }^{6}$ Apesar da recente implementação do trabalho intermitente, no Brasil, a partir de 1995 a rede de lanchonetes McDonald's introduziu o modelo da "jornada móvel e variável". Trata-se de uma experiência semelhante ao contrato de trabalho intermitente no aspecto da máxima flexibilização do tempo de trabalho. De acordo com este modelo contratual, o empregado é contratado sem jornada prefixada, com pagamento apenas das horas efetivamente trabalhadas, sem o cômputo das horas à disposição do empregador (MAEDA, 2017, p. 319).

${ }^{7}$ Art. $443, \S 3^{\text {o: }}$ : Considera-se como intermitente o contrato de trabalho no qual a prestação de serviços, com subordinação, não é contínua, ocorrendo com alternância de períodos de prestação de serviços e de inatividade, determinados em horas, dias ou meses, independentemente do tipo de atividade do empregado e do empregador, exceto para os aeronautas, regidos por legislação própria.

Art. 452-A: O contrato de trabalho intermitente deve ser celebrado por escrito e deve conter especificamente o valor da hora de trabalho, que não pode ser inferior ao valor horário do salário mínimo ou àquele devido aos demais empregados do estabelecimento que exerçam a mesma função em contrato intermitente ou não.
} 
salário mínimo deva ser respeitado não significa, por si, garantia do recebimento do salário mínimo mensal.” (MAEDA, 2017, p. 318).

Além disso, no trabalho intermitente não há horário ou carga horária predefinidos, o trabalhador será convocado para prestar serviços, com até três dias de antecedência. Como não há previsão de "um mínimo de horas trabalhadas ou de remuneração garantida num mês, é possível chegar à absurda situação que antes era simples força de expressão: "pagar para trabalhar" (MAEDA, 2017, p. 319).

Contudo, o trabalhador tem direito a ser informado sobre seu horário de trabalho, sobre seu salário, uma vez que possui necessidades econômicas, pessoais, sociais e familiares que devem ser atendidas.

A contratação intermitente, sem garantias mínimas de chamada e nem de ganho, compromete a subsistência, aprofunda a pobreza, põe em vulnerabilidade o sustento, o planejamento financeiro e a organização familiar, cristaliza o determinismo social atingindo o âmago de proteção laboral da dignidade da pessoa humana (KONRATH, 2017, p. 80).

Assim, além de não assegurar a fruição de direitos fundamentais sociais básicos, o trabalho intermitente coloca o trabalhador numa condição de objeto, um instrumento à disposição da atividade empresarial, na medida em que a norma jurídica autoriza que este seja "utilizado pelo patrão de modo intermitente, quando este bem entender. Quando não estiver sendo usado, ficará o empregado recolhido à sua insignificância.” (ALVES, 2018, p. 13).

Há quem questione a constitucionalidade desta modalidade de contrato de trabalho, sob o argumento de que afronta a dignidade humana (art. $1^{\circ}$, III, da CF), rebaixa o status civilizatório do trabalhador, atentando contra a vedação de tratamento desumano (art. $5^{\circ}$, III) e da previsão constitucional do direito do trabalho enquanto promotor da melhoria da condição social do trabalhador (art. $7^{\circ}$, caput) (MAEDA, 2017, p. 323).

Após realizar um estudo do tema, Amauri Cesar Alves traça um conceito técnicojurídico sobre o novo instituto justrabalhista nos seguintes termos:

Contrato de trabalho intermitente é modalidade contratual trabalhista bilateral e celetista, com prestação de serviço não eventual e em razão da necessidade de trabalho descontínua, mas comum e corriqueira para o empregador que não pode antever, na admissão do empregado, quando se dará e por quanto tempo demandará a prestação laborativa, que é sui generis em relação à previsão de sua duração, marcada pela incerteza do momento exato da necessidade do trabalho e das interrupções, e não pelo número reduzido de horas trabalhadas em um dia, semana ou mês (ALVES, 2018, p. 36-37). 
Partindo-se desses apontamentos, depreende-se que o objetivo principal foi repassar ao trabalhador os riscos da atividade econômica, o que até então não era possível nas relações de emprego, de acordo com os artigos $2^{\circ}$ e $3^{\circ}$ da CLT. ${ }^{8}$

Destaca-se, ainda, que esta modalidade de trabalho remonta à experiência do Reino Unido com o "zero-hour contract" ou "contrato zero hora", 9 o qual não assegura ao empregado nenhuma carga fixa de trabalho, mas tão somente "um liame entre as partes para que, acaso o empregador necessite dos serviços do trabalhador ele o convoca e remunera pelo tempo efetivamente laborado.” (CHARÃO; VILLATORE, 2018, p. 119).

Outra crítica dirigida ao contrato de trabalho intermitente reside no fato de que a lei trabalhista brasileira, diferente das versões portuguesas ${ }^{10}$ e italianas, foi genérica, autorizando sua celebração em qualquer ramo da atividade econômica (exceto para a categoria dos aeronautas), o que pode ensejar a substituição da mão de obra regular por contratação intermitente (PINHEIRO, 2017, p. 198). Contudo:

[...] a formação do contrato intermitente há de estar umbilicalmente ligada à intermitência do serviço, à existência de uma demanda peculiar, caso contrário o contrato intermitente será apenas um meio de precarização das relações de trabalho e empobrecimento do trabalhador (CHARÃO; VILLATORE, 2018, p. 126).

Por fim, apresentado o conceito de trabalho intermitente, bem como as principais críticas dirigidas a esta modalidade de contratação, na sequência far-se-á uma leitura do tema à luz do direito à inclusão socioeconômica.

\section{O TRABALHO INTERMITENTE À LUZ DO DIREITO À INCLUSÃO SOCIOECONÔMICA}

\footnotetext{
${ }^{8}$ Art. $2^{\circ}$ - Considera-se empregador a empresa, individual ou coletiva, que, assumindo os riscos da atividade econômica, admite, assalaria e dirige a prestação pessoal de serviço.

Art. $3^{\circ}$ - Considera-se empregado toda pessoa física que prestar serviços de natureza não eventual a empregador, sob a dependência deste e mediante salário.

${ }^{9}$ Com relação ao contrato-zero, muitos o concebem como o contrato de zero garantias: "não há garantia de trabalho mínimo nem de quando será convocado para trabalhar. O empregado é contratado com o contrato já suspenso desde a admissão." (CASSAR, 2017, p. 435). A autora vai mais além, descrevendo o contrato intermitente como: "[...] a formalização do "bico" ou como chamam alguns é o "contrato-zero", garantindo ao trabalhador, por um lado, direitos típicos dos empregados e por outro, características dos autônomos, com a imprevisibilidade e precariedade do trabalho de um biscateiro, que não sabe quando e por quanto tempo irá trabalhar, nem se será chamado.” (CASSAR, 2017, p. 435).

${ }^{10} \mathrm{~A}$ título de exemplo, em Portugal, o Código de Trabalho no artigo 157 admite o trabalho intermitente apenas em empresa que exerça a atividade com descontinuidade ou intensidade variável.
} 
O Estado Brasileiro deve assegurar a concretização dos direitos fundamentais, valendo-se de políticas públicas e de marcos regulatórios positivos, sem esquecer da observância da dignidade da pessoa humana, princípio fundante da República Federativa do Brasil.

Partindo disso, tem-se que o direito à inclusão socioeconômica é direito fundamental, nos termos do artigo $3^{\circ}$, incisos I e III, da CF/88. ${ }^{11}$ Deve o Estado, observado os ditames da justiça social, conciliar direitos sociais com a ordem econômica, segundo o caput do artigo 170 da $\mathrm{CF} / 88^{12}$, e o trabalho com o capital, garantindo aos trabalhadores direitos sociais e ao setor empresarial oportunidades econômicas.

Para tanto, May, Possamai e Ramos, após realizarem estudo sobre o tema, propõem "que se chame a correlação oportunidade econômica e direito social de "direito à inclusão socioeconômica” (MAY; POSSAMAI; RAMOS, 2018, p. 102). Dessa forma:

O direito à inclusão socioeconômica é o direito à inclusão social e econômica. A primeira já foi amplamente estudada por diversos autores. Quanto à segunda, tratase da criação de oportunidades ou meios para que o indivíduo instrumentalize sua vida digna. Uma vida em que goze dos benefícios do contrato social, autodeterminese e seja independente. Uma vida em que ele contribua para o aprimoramento social, em que ele contribua financeiramente para a manutenção de si e dos seus, em sociedade. Engloba o direito de usufruir dos benefícios do bem-estar social, preservando a autoestima e a altivez de sua contribuição profissional para o pagamento dos benefícios coletivos, dos quais usufrui diretamente ou não.

$\mathrm{O}$ direito à inclusão socioeconômica se materializa nas condições constitucionais preparatórias ou imediatas que permitem ao indivíduo empregar-se ou empreender, ou seja, ter acesso ao trabalho, do qual possa tirar seu sustento. $\mathrm{O}$ direito à inclusão socioeconômica, mais que um direito benéfico ao indivíduo, é, em si, um direito benéfico à sociedade, pois o indivíduo ativo contribui significativamente para o sucesso do bem-estar social. Assegurado esse direito, o indivíduo se torna menos dependente do sistema social de proteção do Estado. De um ser passivo, acusado de parasitagem e vítima de esmolas estatais, torna-se um agente ativo, contribuinte para o sucesso social (MAY; POSSAMAI; RAMOS, 2018, p. 102-103).

Partindo deste conceito, cabe verificar se o trabalho intermitente permite uma efetiva inclusão socioeconômica ao trabalhador.

Como visto no tópico anterior, sem muito esforço, percebe-se que o contrato de trabalho intermitente não assegura condições mínimas para a existência digna do trabalhador, na medida em que a remuneração auferida não garante a subsistência deste e de sua família

\footnotetext{
${ }^{11}$ Art. $3^{\circ}$ Constituem objetivos fundamentais da República Federativa do Brasil:

I - construir uma sociedade livre, justa e solidária; [...] III - erradicar a pobreza e a marginalização e reduzir as desigualdades sociais e regionais.

${ }^{12}$ Art. 170. A ordem econômica, fundada na valorização do trabalho humano e na livre iniciativa, tem por fim assegurar a todos existência digna, conforme os ditames da justiça social, [...].
} 
com pagamento do salário mínimo mensal constitucional (art. $7^{\circ}$, IV e VII) nem o acesso a direitos sociais como trabalho, moradia, alimentação, saúde, segurança (art. $6^{\circ}$, caput).

A respeito da dignidade humana, Sarlet (2012, p. 77) sustenta tratar-se de uma qualidade intrínseca da pessoa humana, algo que simplesmente existe, sendo irrenunciável e inalienável, constituindo elemento que qualifica o ser humano como tal e dele não pode ser destacado.

Além disso, a dignidade engloba o respeito e a proteção da integridade física e corporal do indivíduo, razão pela qual para sua preservação, torna-se indispensável garantir condições justas e adequadas de vida para o indivíduo e sua família.

Nesse contexto, assumem relevo de modo especial os direitos sociais ao trabalho, a um sistema efetivo de seguridade social e, em última análise, à proteção da pessoa contra as necessidades de ordem material e à asseguração de uma existência com dignidade.

Dessa forma, conclui-se que o trabalho intermitente nada tem a ver com a garantia de uma inclusão socioeconômica, estando muito longe do conceito apresentado, pois sequer assegura ao trabalhador meios para que ele instrumentalize uma vida digna.

Diante disso, questiona-se: para enfrentar os altos índices de desemprego no Brasil não seria o caso de adotar políticas públicas de geração de trabalho e renda ao invés da tendência flexibilizante das relações de trabalho, por meio de mudanças no conteúdo da própria legislação?

Embora a necessidade de reformar as leis trabalhistas venha sendo apresentada no Ocidente como um caminho sem alternativas, a experiência internacional mostra que os benefícios dessa "reforma trabalhista" brasileira são, no mínimo, incertos.

Nesse sentido, interessante destacar o caso da Espanha, que teve sua proposta de reforma trabalhista convertida em lei em 2012. ${ }^{13}$ Segundo pesquisa realizada pelo pesquisador Leães, da Fundação de Economia e Estatística do Rio Grande do Sul, passados mais de cincos anos desde a ratificação da lei na Espanha, os dados parecem indicar um quadro ambíguo, caracterizado pelo aumento concomitante da criação de empregos e precarização das relações de trabalho. ${ }^{14}$

\footnotetext{
${ }^{13}$ Acerca do tema, "em fevereiro de 2012, na Espanha, foi convertida em lei a proposta de reforma trabalhista encabeçada pelo governo de Mariano Rajoy, do Partido Popular (PP). Esse projeto se situa em um quadro maior de movimentos de flexibilização do mercado de trabalho, como no México, no Chile, na Argentina e, destacadamente, no Brasil, de modo que não pode ser considerado sui generis.” (LEÃES, 2018, p. 09).

${ }^{14}$ Segundo a pesquisa, na Espanha, "ao final de 2016, em comparação com o último trimestre de 2011, o número de ocupados cresceu 350.000, e o de assalariados foi ampliado em 250.000. Assim, a taxa de desemprego caiu de um patamar de $24,8 \%$ para $18,5 \%$, o que tem sido saudado pelos entusiastas das atualizações na legislação. Por
} 
Segundo o especialista, a relação direta entre a reforma e a geração de empregos não é tão evidente assim, isso porque, apesar do cenário positivo quanto à criação de vagas, o período em que a reforma esteve em vigor na Espanha mostra um cenário dúbio:

[...] embora a taxa de desemprego tenha, com efeito, caído desde 2011, observa-se que seu nível subiu até a metade de 2014 - trajetória que só se inverteu com a retomada do crescimento econômico nesse ano, ou seja, os trimestres imediatamente posteriores à reforma sinalizam um quadro contrário às expectativas de seus defensores. Como a correlação entre o crescimento econômico e a criação de empregos é consagrada na literatura especializada, permanece incerto, ainda que plausível, afirmar que a diminuição da taxa de desemprego tenha sido causada pela reforma trabalhista (LEÃES, 2018, p. 09).

Dessa forma, no caso espanhol, o vínculo entre os dois processos só ocorreu após o surgimento de um fenômeno oposto ao previsto, o que indica que a geração de empregos pode ter sido decorrente de um terceiro fator, independente da reforma.

Nessas circunstâncias, a pesquisa revela que os benefícios da reforma trabalhista para os trabalhadores espanhóis parecem ambíguos, uma vez que:

[...] a geração de empregos não necessariamente está vinculada à alteração na legislação. Em contraposição, os prejuízos são cristalinos, pois essas mudanças encetaram precarizações nas relações de trabalho e nas contrações salariais (LEÃES, 2018, p. 10).

No caso do Brasil, em que a reforma trabalhista entrou em vigor em novembro de 2017, com a promessa de vencer o desemprego por meio da geração de postos de trabalho, os dados estatísticos divulgados pelo $\mathrm{CAGED}^{15}$ e pelo IBGE $^{16}$ ainda são muito incipientes, não sendo possível avaliar efetivamente os efeitos do contrato intermitente na redução do desemprego ou da informalidade. ${ }^{17}$

Contudo, embora decorrido pouco tempo da implementação da reforma trabalhista, os críticos à reforma argumentam que ela não conseguiu sequer aumentar os empregos precários, uma vez que nem estes tiveram “elevação substancial capaz de dar ao governo dados substanciais de melhora nos índices de emprego para fazer propaganda favorável à Reforma.” (CACOSSI, 2018).

outro lado, avançou a contratação de funcionários temporários e de trabalhadores de meio período, fazendo com que o salário médio anual seja, atualmente, 800 euros menor do que o de 2011.” (LEÃES, 2018, p. 09).

${ }^{15}$ Cadastro Geral de Empregados e Desempregados.

${ }^{16}$ Instituto Brasileiro de Geografia e Estatística.

17 Segundo dados do CAGED, logo após a entrada em vigor da reforma trabalhista, o Brasil teve uma queda acentuada no número de empregos formais. Ainda em novembro de 2017, quando a lei entrou em vigor, o saldo foi de -6.799 empregos formais. No mês seguinte, o saldo foi de -340.218 , o pior resultado do ano. Ainda, dados do IBGE, divulgados recentemente, apontam que o desemprego voltou a crescer no primeiro trimestre de 2018. 
Assim, necessário se faz pensar em caminhos alternativos de geração de trabalho e renda como fonte de subsistência para trabalhadores excluídos do mercado formal de trabalho. Nesse sentido, entende-se que experiências associativistas podem contribuir para o estabelecimento de uma economia solidária, ${ }^{18}$ diferenciando-se das normatizações ditadas pelo mercado capitalista, ainda que a realização da produção venha ocorrer neste mesmo mercado.

Aliado a esta proposta, ao tratar de uma política de inclusão, o economista Pochmann aponta que no Brasil há dois problemas a serem resolvidos: o padrão de financiamento e o nível de proteção social a ser assegurado a todos. Segundo o pesquisador, o volume de gasto social no Brasil não é desprezível; contudo, é preciso ampliar as bases do financiamento do gasto com as políticas sociais e do trabalho. Ou seja, "fazer mais e melhor do mesmo recurso existente, elevando a efetividade, a eficácia e a eficiência das políticas pública nacionais.” (POCHMANN, 2003, p. 34).

Por fim, conclui-se que uma política de inclusão depende muito mais de uma vontade política dos governantes, de uma expansão econômica, da criação de alternativas dignas para inserção do indivíduo no mercado de trabalho, do que do afrouxamento das regras de proteção aos trabalhadores.

\section{CONCLUSÃO}

A reforma trabalhista, aprovada com o propósito de retomar o crescimento econômico e enfrentar o desemprego, até o presente momento, pelos dados obtidos junto ao CAGED e o IBGE, ainda não alcançou tais objetivos. Além disso, a realização de uma reforma não é capaz, por si só, de gerar empregos. Tal efeito está muito mais ligado a aspectos econômicos do que resultado das condições institucionais que regulam as relações de trabalho.

Com relação ao contrato de trabalho intermitente, como visto, ele contribui para aumentar a precariedade como um todo, além de fragmentar e fragilizar a classe trabalhadora, aniquilando com muitos de seus direitos. Somado a isso, as experiências de trabalho intermitente implementadas em alguns países europeus apontam que mesmo lá ocorreu uma redução da remuneração, um aumento da rotatividade e da sensação de insegurança, com reflexos no consumo e na programação da vida do trabalhador.

\footnotetext{
${ }^{18}$ Para maior aprofundamento no tema, recomenda-se a leitura do livro "Introdução à Economia Solidária", de Paul Singer.
} 
Portanto, o trabalho intermitente, tal como colocado pela reforma, está na contramão daquilo que se entende por inclusão socioeconômica e trabalho digno, pois não permite sequer o mínimo: que o trabalhador alcance dignidade de subsistência própria e de sua família.

Finalmente, feitas estas considerações, necessário se faz implementar políticas públicas de geração de trabalho e renda, as quais dependem muito mais de uma vontade política dos governantes, de uma expansão econômica, da criação de alternativas dignas para inserção do indivíduo no mercado de trabalho, do que de uma alteração legislativa.

\section{REFERÊNCIAS}

ALVES, Amauri Cesar. Trabalho intermitente e os desafios da conceituação jurídica. Revista Síntese: trabalhista e previdenciária. São Paulo, v. 29, n. 346, p. 9-39, abr. 2018.

BRANCO, Iracema Keila Castelo; MIEBACH, Alessandro Donadio. Um primeiro olhar sobre a reforma trabalhista e seus impactos econômicos. Revista Eletrônica da Fundação de Economia e Estatística, Porto Alegre, v. 3, n. 2, p. 18-20. 2018. Disponível em: < http://panoramainternacional.fee.tche.br/>. Acesso em: 14 jun. 2018.

CACOSSI, Breno. Dados do IBGE: Reforma Trabalhista aumenta precarização do trabalho e eleva desemprego. Esquerda Diário, 29 mar. 2018. Disponível em: <http://www.esquerdadiario.com.br/Dados-do-IBGE-Reforma-Trabalhista-aumentaprecarizacao-do-trabalho-e-eleva-desemprego>. Acesso em: 02 jun. 2018.

CÂMARA DOS DEPUTADOS. Altera o Decreto-Lei n ${ }^{\circ} 5.452$, de $1^{\circ}$ de maio de 1943 Consolidação das Leis do Trabalho, e a Lei no 6.019, de 3 de janeiro de 1974, para dispor sobre eleições de representantes dos trabalhadores no local de trabalho e sobre trabalho temporário, e dá outras providências. Parecer da comissão especial. Relator: Deputado Rogério Marinho. 2017. Disponível em:

<http://www.camara.gov.br/proposicoesWeb/prop_mostrarintegra?codteor=1544961\&filenam $\mathrm{e}=$ Tramitacao-PL+6787/2016> . Acesso em: 14 jun. 2018.

CASSAR, Vólia Bomfim. Uma das novidades da reforma trabalhista:

o contrato intermitente. LTr Suplemento Trabalhista, São Paulo, v. 53, n. 084, p. 433-436, nov. 2017.

CHARÃO, Anderson Pereira; VILLATORE, Marco Antônio César. O contrato de trabalho intermitente na reforma laboral e os danos ao trabalhador. A reforma trabalhista na visão acadêmica. Porto Alegre: Verbo Jurídico, 2018. p. 119-131.

INSTITUTO BRASILEIRO DE GEOGRAFIA E ESTATÍSTICA. Desemprego volta a crescer no primeiro trimestre de 2018. Agência IBGE Notícias. Disponível em: $<$ https://agenciadenoticias.ibge.gov.br/agencia-noticias/2012-agencia-denoticias/noticias/20995-desemprego-volta-a-crescer-no-primeiro-trimestre-de-2018.html >. Acesso em: 02 jun. 2018. 
KONRATH, Ângela Maria. O contrato de trabalho intermitente. Comentários à Lei 13.467/17: contribuições para um enfrentamento crítico. Porto Alegre: HS, 2017. p. 78-81.

LAKATOS, Eva Maria; MARCONI, Marina de Andrade. Fundamentos de metodologia científica. São Paulo: Atlas, 2003.

LEÃES, Ricardo Fagundes. Reforma trabalhista espanhola: perdas garantidas, benefício incertos. Revista Eletrônica da Fundação de Economia e Estatística, Porto Alegre, v. 3, n. 2, p. 9-10. 2018. Disponível em: < http://panoramainternacional.fee.tche.br/>. Acesso em: 14 jun. 2018.

MAEDA, Patrícia. Contrato de trabalho intermitente. Resistência: aportes teóricos contra o retrocesso trabalhista. São Paulo: Expressão Popular, 2017. p. 317-325.

MAY, Yduan de Oliveira; POSSAMAI, Angélica Pereira; RAMOS, Thaís Scarpatto. Direitos Socioeconomicos. Curitiba: Multideia, 2018.

MINISTÉRIO DO TRABALHO. Programa de disseminação das estatísticas do trabalho. Disponível em: <http://pdet.mte.gov.br/caged>. Acesso em: 02 jun. 2018.

ORDEM DOS ADVOGADOS DO BRASIL, 2017, Paraná. VI Conferência estadual da advocacia da Ordem dos Advogados do Brasil. Painel Reforma Trabalhista: avanços e retrocessos. Disponível em: < https://www.oabpr.org.br/reforma-trabalhista-inchou-clt-e-naoaproximou-do-direito-privado>. Acesso em: 23 jul. 2018.

PINHEIRO, Iuri Pereira. Contrato de trabalho intermitente. Reforma trabalhista e os novos direitos material e processual do trabalho. Porto Alegre: Verbo, 2017. p. 185-205.

POCHMANN, Marcio. Nova política de inclusão socioeconômica. Revista de Economia Mackenzie, São Paulo, v. 1 n. 1, p. 27-36, 2003.

SARLET, Ingo Wolfgang. A eficácia dos direitos fundamentais: uma teoria geral dos direitos fundamentais na perspectiva constitucional. 11. ed. rev. e atual. Porto Alegre: Livraria do Advogado, 2012. 504 p.

SEVERO, Valdete Souto. Reforma trabalhista: um retrocesso dos direitos sociais. Porto Alegre: 2018. Revista Eletrônica da Fundação de Economia e Estatística, Porto Alegre, v. 3, n. 2, p. 11-14. 2018. Entrevista concedida a Bruno Mariotto Jubran. Disponível em: < http://panoramainternacional.fee.tche.br/>. Acesso em: 14 jun. 2018. 